2. Илларионова Н.Н. Формирование компонентов музыкального вкуса эстрадных вокалистов в образовательной среде вуза // Ануфриев Е.А., Ануфриева Н.И., Драйчук Т.С., Илларионова Н.Н., Корсакова И.А., Лысакова О.Н., Славина Е.В., Слуцкая И.И., Цилинко А.П.Щербакова А.И., Ющенко Н.С. Формирование профессиональной компетентности современного музыканта: коллективная монография. М.: РГСУ, 2014. С. $198-225$.
3. Материалы мастер-класса преподавателя государственного музыкального училища эстрадно-джазового искусства им. Гнесиных А.С. Полякова. М., 2017. 24 с.

4. Никитин В.В. Особенности эстрадного вокала для начальных классов школ искусств: метод. разработка. М., 2017. 13 с.

5. Поляков А.С. Методика преподавания эстрадно-джазового пения. М., 2008. 44 с

\title{
СОНАТИНЫ ДЛЯ СКРИПКИ И ФОРТЕПИАНО Е.СВЕТЛАНОВА КАК ОТРАЖЕНИЕ ОСОБЕННОСТЕЙ ЕГО КАМЕРНО-ИНСТРУМЕНТАЛЬНОГО СТИЛЯ
}

\section{АННОТАЦИЯ}

Бойко Валентина Леонидовна

Профессор, кандидат философских наук, Сибирский государственньй институт искусств имени Д.Хворостовского, г.Красноярск

Литвинцева Наталья Ивановна доцент кафедры камерного ансамбля и кониертмейстерской подготовки, Сибирский государственньй институт искусств имени Д.Хворостовского, 2.Красноярск

В данной работе анализируется камерно-инструментальный стиль композитора Е.Светланова на примере его сочинений - Сонатины для скрипки и фортепиано.

В содержании статьи раскрываются условия для решения стоящей перед исполнителями задачи овладение навыками игры в ансамбле, наиболее полное раскрытие музыкально-художественных образов исполняемых произведений.

Опираясь на требования государственных образовательных стандартов в области подготовки музыкантов-инструменталистов нового качественного уровня, авторами статьи предлагаются методические рекомендации для решения стоящей перед педагогами профессионального музыкального образования задачи - всестороннее развитие способностей творческой индивидуальности каждого из студентов, занимающихся ансамблевым музицированием.

\section{ABSTRACT}

In this article Sonatinas for violin and piano of Y.Svetlanov are the subject of the research.

This paper examines the conditions for realization a problem of the the important sphere of professional activity - ensemble playing.

Based on the requirements of federal educational standards in the training of musicians-instrumentalists of the new qualitative level, the contents of the article reveals the recommendations for the solution facing the problem of professional musical teachers - a comprehensive development of abilities, the most complete disclosure of the creative personality of students in the ensemble playing.

Ключевые слова: Ансамблевое музицирование; сонатина; исполнительское искусство; композитор; художественный образ.

Keywords: The ensemble playing; sonatina; the performing art; the composer; the artistic image.

Разносторонность и пасштабность творческого дарования Евгения Федоровича Светланова - одного из известных музыкантов XX века - просто потрясает. Дирижер, композитор, исполнитель, публицист, вдохновенный поэт, художник, спортсмен - это все о нем! Однако, Е.Ф.Светланов, которого мы знаем как прекрасного дирижера, в первую очередь, считал себя композитором. В своих воспоминаниях музыкант отмечает: «Обо мне охотно говорят как о дирижере, пианисте, а уж потом как о композиторе, но ведь я и не предполагал посвящать себя дирижированию. Прежде всего, я композитор, это моя первая и

${ }^{1}$ Е. Ф. Светланов - единственный дирижер, кто реализовал идею «Антологии русской главная профессия, я стал сочинять музыку еще до того, как вообще взялся за дирижерскую палочку» $[1$, c. 29$]$

В истоках композиторского стиля Е. Ф. Светланова можно обнаружить глубочайшую связь с лучшими традициями русской романтической музыки ${ }^{1}$. Написанные во второй половине XX века его произведения сочинялись в «традиционном ключе». Лишенные «авангардных» и модернистских поисков простые и понятные лирические темы, которыми изобилуют его музыкальные произведения, волнуют исполнителей и слушателей. Евгений Федорович

симфонической музыки», записав со своим оркестром почти все произведения выдающихся русских и советских композиторов. 
как-то сказал: «В композиторском (творчестве), с моей точки зрения, исчерпаны все эксперименты в смысле усложнения музыкальной речи, поскольку эти эксперименты в свое время уже привели некоторых авторов к абсурду.... Надо писать простую, понятную человеку музыку, которая взволнует его, дойдет до его сердца. В этом я вижу главную задачу композитора, в этом направлении я и стараюсь работать» $[1$, с. 44$]$.

Среди большого композиторского наследия Евгения Светланова мы выделяем лишь небольшую часть - его камерно-инструментальные сочинения, а это: сонаты и пьесы для виолончели, альта, кларнета с фортепиано, произведения для скрипки и фортепиано и другие. Сам автор признавался, что очень любит скрипку. Камерная музыка для скрипки и фортепиано в композиторском творчестве Е.Светланова представлена сонатой (посвященной Н.Я. Мясковскому), пьесами - «Два простых напева», «Вальс», «Ария», циклом «Пять мелодий», а также двумя сонатинами.

В рамках одной статьи невозможно проанализировать все особенности камерноинструментального творчества Е.Ф.Светланова. Поэтому авторы данной работы обращаются непосредственно к двум сонатинам для скрипки и фортепиано, и на этом музыкальном материале рассматривают особенности композиторского стиля Е.Светланова, анализируя ладовую и мелодико-гармоническую основу, ассоциативнохудожественные музыкальные образы, предлагая методические рекомендации и палитру исполнительских решений.

Итак, обратимся к анализу первого сочинения.

Сонатина для скрипки и фортепиано №1 представляет собой 3 -х частный цикл с подвижными крайними частями и неторопливой напевной средней частью.

Главная партия первой части сочетает в себе изломанный мелодический рисунок с прихотливыми, разнообразными штрихами и лирически певучим мотивом. «Взбегающие», как бы устремленные вперед восьмые в партии рояля (первый раздел) в сочетании с партией скрипки создают характер юношеской взволнованности, ощущение свежего весеннего ветра. В побочной партии движение замедляется (стоит авторская ремарка meno), в партии фортепиано восьмые сменяются спокойными четвертями. Простые повторяющиеся ритмические и синтаксические структуры указывают на песенный характер мелодии. Тема переходит к партии рояля, где ее сопровождает «вокальный» подголосок скрипичной партии. Интересны гармонии, которыми автор отмечает переходы между разделами первой части. На границе частей нас всегда встречает необычайно красочная гармония с неаккордовыми и альтерированными звуками, «уводящая» в тональности «дальнего» родства. Как будто каждый раз открывается дверь в необычное сказочное пространство.

Разработка строится на материале главной и побочной партий. Основные темы «попадают» в далекие диезные и бемольные тональности, сохраняя при этом свои первоначальные характеристики. Главная партия - многократно повторяющийся первоначальный скерцозный мотив звучит по очереди - от скрипки к роялю, и от рояля к скрипке. В кульминации тема звучит у фортепиано, причудливо украшенная необычными гармониями и хроматическими скрипичными «глиссандо».
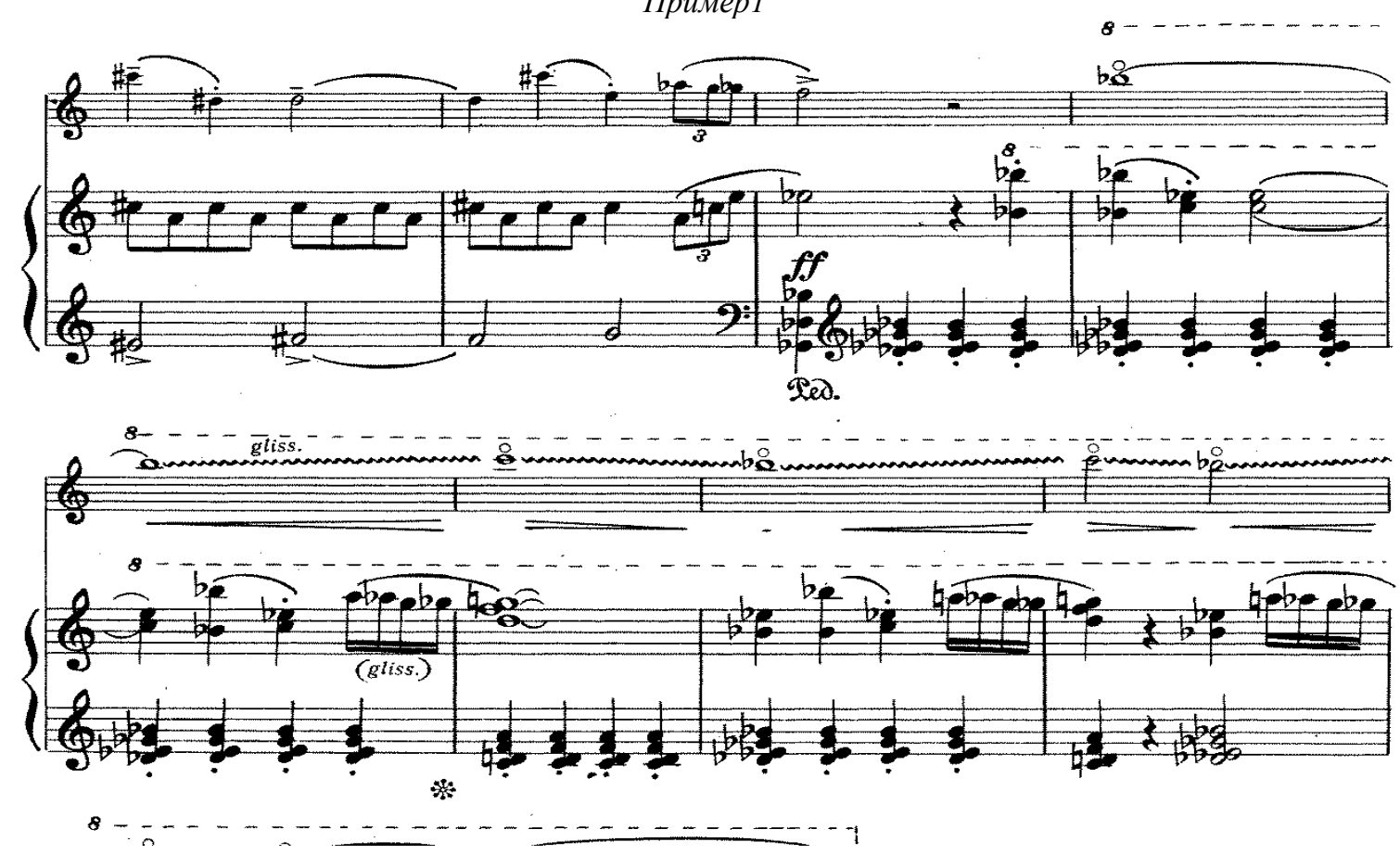

Побочная партия в разработке проводится в «густой» бемольной тональности, сопровождаемая триольным «покачиванием» в фортепианной партии. И снова необычный аккорд возвращает нас 
в основную тональность. В репризе главная партия повторяется, немного фактурно изменив аккомпанемент, а побочная партия звучит в тональности на полтона ниже (по отношению к первому разделу). Небольшое заключение возвращает нас в тональность до мажор, но удивительно «сказочные» гармонии, «таинственное» стаккато в партии рояля, «внезапно исчезающая» динамика говорит нам о том, что повествование не закончено.

Жанровая основа второй части - народная песня. Об этом говорит обилие кварто-квинтовых интонаций, вариационный способ развития, простой аккомпанемент - «бас-аккорд». Как уже отмечалось ранее, близость русской народной интонации - основная черта творчества Е. Светланова. Красота и поэтичность его мелодий отсылает нас к образу Родины, русских просторов. В этой связи любопытно воспоминание вдовы известного музыканта - Нины Николаевой Светлановой. Она пишет: «...А однажды мы приехали на Красноярскую ГЭС, и нам стали показывать всю панораму под музыку симфонии Светланова. «Это специально?» - удивился он. Оказалось, - его музыку довольно часто использовали в фильмах о природе, даже не называя имени ее автора. Но он был этим очень доволен, считая, что от композитора на земле чтото все-таки остается» [2].

Третья часть - жанровая зарисовка. В стремительном беге как в калейдоскопе сменяют друг друга три основные темы и их видоизмененные «модификации». Многократные проведения тем позволяют предположить, что форма части имеет черты рондо-сонаты. Первая скерцозная тема заряжена юмором, стремительным движением стаккатированного бурдона в аккомпанементе. Начиная бег по ломаному трезвучию фа диез мажора, сочетаясь с квинтой основной тональности - соль мажор - в партии рояля- звучит главная партия третьей части. В партии скрипки - неожиданные мелодические повороты, частая смена штрихов. Связующая тема носит танцевальный характер, в ней слышится и плавные движения, и энергичный танец «вприсядку». Побочная партия - протяжная песня на фоне стремительного движения, её звучание невольно ассоциируется с картиной русской тройки и открытого широкого пространства. Каждое проведение побочной партии набирает силу, мощь, кульминационное её проведение - самая яркая точка части и всей сонатины.

В заключительном разделе сочинения композитор не дает никаких авторских ремарок. Но если обратиться к интерпретации этой сонатины в исполнении камерного ансамбля Е.Светланов Э.Грач, то становится совершенно очевидно, что мощное accelerando на заключительных восходящих пассажах (присутствующее в записи данного дуэта) - это реализация «тайного» авторского замысла.

Перейдем к анализу Сонатины № 2 для скрипки и фортепиано.

Это сочинение имеет авторский подзаголовок - «Сонатина-элегия». Стройная одночастная композиция очень компактна, форма ее подчинена логике мелодического развития основных тем. И здесь композитор Е. Светланов проявил себя, прежде всего, как мелодист. «Увлекаясь гармоническими находками, игрой ритма, оркестровыми красками, мы упускаем из поля зрения самое главное - выразительность мелодии, - пишет Е.Светланов. - И мне хочется призвать в первую очередь молодых музыкантов к тому, чтобы мелодии, которые они сочиняли, были бы певучими, предельно насыщенными и широкими по дыханию» [1, с. 43].

Открывается сонатина выразительным фортепианным вступлением, после которого звучит скрипка. Тема в партии скрипки льется широко, достигая своей кульминации в заключении (перед побочной партией). Большие музыкальные построения - «кирпичики фраз» - главной партии, сопровождаемые «плавающими» шестнадцатыми и выразительными мелодическими подголосками в партии фортепиано, как бы «цепляются» друг за друга в синкопирующем ритме. В кульминации тема главной партии звучит каноном в партиях фортепиано и скрипки. После этого поток шестнадцатых в партии фортепиано начинает «притормаживать» игривыми синкопами и после скрипичного соло наступает побочная партия, которая звучит спокойно и умиротворенно. Мелодия побочной партии проводится в низком и среднем регистре скрипки, без резких подъемов, как бы вращаясь на нескольких повторяющихся интонациях. Непрерывное движение шестнадцатых сменяется размеренным аккордовым аккомпанементом восьмыми, что придает побочной партии целостность - она звучит как на «одном дыхании».

Появлением темы вступления открывается разработка. Здесь необходимо заметить, что имея много общего с главной и побочной партиями экспозиции (общность в звучании придает затактовая ритмическая формула), вместе с тем музыкальный материал разработки достаточно самостоятелен. Скрипка и фортепиано как бы соревнуются друг с другом, происходит динамический накал - взлет партии скрипки и фортепиано охватывает огромный диапазон регистров и завершается акцентированными октавными унисонами - это кульминация, своего рода точка «волотого сечения) 
Пример 2

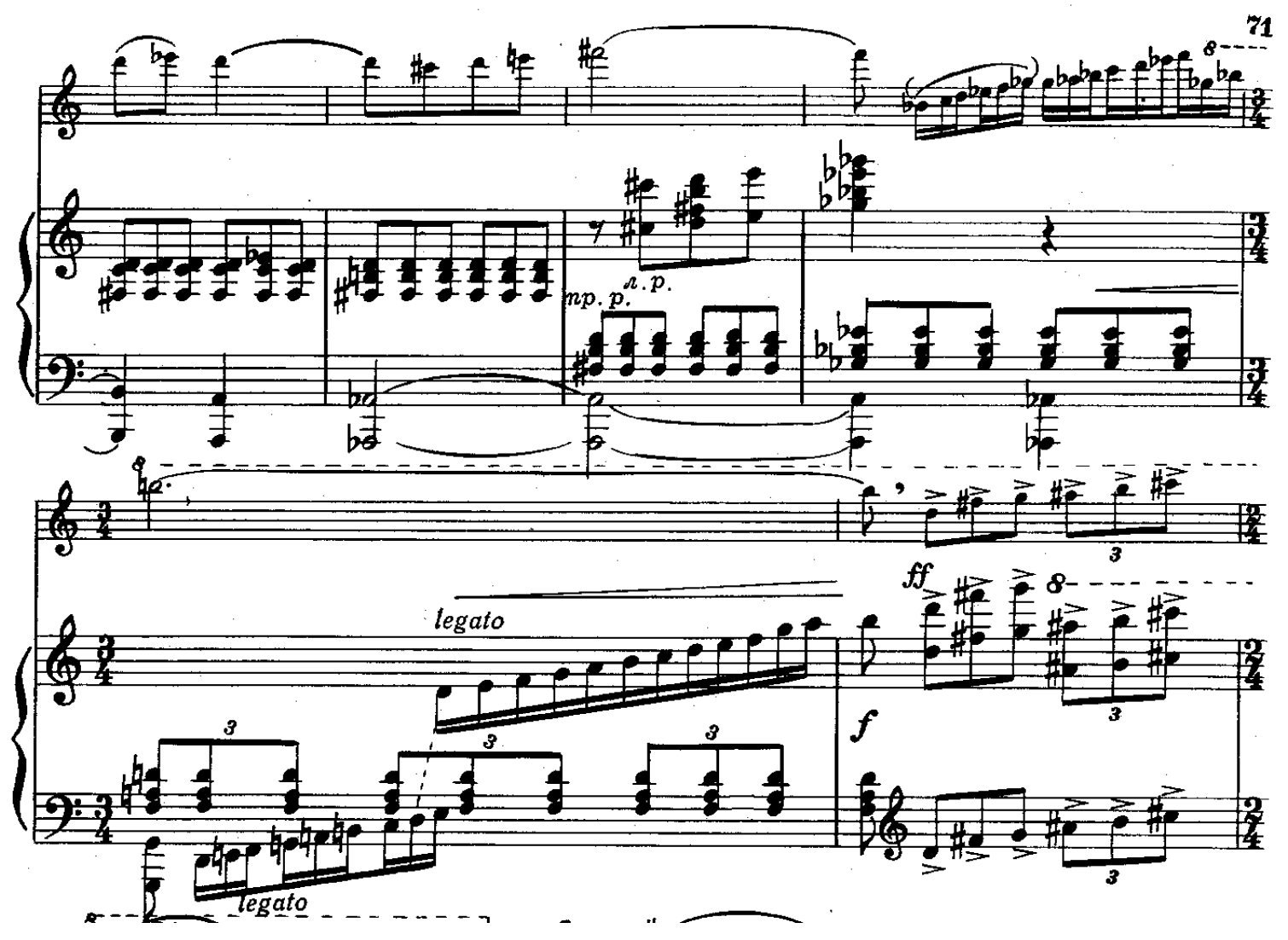

Четко выстроенная кульминация придает всему произведению стройную, симметричную форму. А Е.Ф.Светланов, по воспоминаниям его современников, был мастером по выстраиванию композиционной формы, приданию музыкальному произведению целостности.

Среди музыкантов, работающих с Е. Светлановым, бытовало выражение «светлановские кульминации». Так Родион Щедрин отмечает: «Характерная черта ... почерка Светланова: точное, безошибочное чувство кульминации... Тут, конечно, играет роль и композиторское чутье Евгения Светланова» [1, с. 14].

В заключительном разделе Сонатины-элегии звучат начальные интонации главной партии. Скрипка уходит в низкий регистр и исчезает - игра на флажолете - растворяясь в заключительном аккорде фортепиано.

Обобщая все вышесказанное, хотелось бы отметить, что Сонатины для скрипки и фортепиано Е.Ф. Светланова - на примере которых были рассмотрены особенности камерноинструментального стиля композитора - являются замечательными образцами ансамблевой литературы. Партии ансамблистов в данных произведениях имеют абсолютно равнозначный характер. Меняясь «ролями», передавая друг другу функции мелодии и аккомпанемента, партии скрипки и фортепиано в тесном контакте выстраивают кульминации, «договаривают» музыкальные фразы. Несмотря на лаконичность самих произведений, исполнители могут научиться многим основным техническим качествам, необходимых при игре в ансамбле. А уровень сложности позволяет включить эти произведения в репертуар рабочей программы по курсу «камерный ансамбль» для студентов колледжа и младших курсов ВУЗа.

В процессе изучения данных произведений авторы статьи (в качестве рекомендации) предлагают ознакомиться с аудио-видеозаписями Сонатин для скрипки и фортепиано в исполнении Евгения Светланова и Эдуарда Грача. Эта музыкально-художественная интерпретация отличается яркой убедительностью, разнообразием в характеристике тем, мощным и вместе с тем благородным звучанием всех кульминаций, увлеченным погружением в музыкальный материал.

Индивидуальность Е.Ф. Светланова, которому были чужды крайности в трактовке как своих, так и чужих произведений, - по мнению Ф.Мансурова «гармонично, счастливо сочетает огромный внутренний темперамент с высоким интеллектом, лирическую одухотворенность с поразительно ясным ощущением композиции» [1, с. 33].

В заключении хотелось бы воспроизвести небольшое воспоминание Нины Александровны Николаевой-Светлановой. Она пишет: «Евгений Федорович был очень ранимый человек, он переживал, что его сочинения не исполняются. И все же он считал себя в первую очередь композитором. Забавный случай произошел с ним в Америке, когда он впервые приехал дирижировать знаменитым Филадельфийским 
оркестром. Оркестранты встретили его спесиво, и он сказал им: «А я не дирижер, я вообще композитор», чем только усугубил ситуацию. Однако после исполнения симфонии Чайковского они просто кричали от восторга, спрашивая: «Почему мы до сих пор не знали этого дирижера?» А Светланов ответил: «Потому что я в первую очередь - композитор» [2].

\section{ЛИТЕРАТУРА}

1. Евгений Светланов: дирижер, композитор, пианист/ Сост. П. В. Лукьянченко. - М: Музыка, 1987.- 159c.

\section{ИНТЕРНЕТ-РЕСУРСЫ}

2. Тарасова Е. Концерт-монография «Евгений Светланов- композитор» http://muzkarta.info/novost/kontsertmonografiya-yevgeny-svetlanov

\title{
SOLAR PATTERNS IN THE TRADITIONAL TARAZ OF WOMEN OF NEW JUGHA
}

\author{
Knkush Malkhasyan \\ Architecture and Construction \\ Armenian National University \\ Associate Professor
}

\section{ANNOTATION}

The article revises the use of sun symbol in New Jugha. There are comparisons and parallels between similar decorations in different types of arts, with pictures. There is a reference of scientific articles and sources (online and printed), which have been used for the full presentation of the material. The article presents historical overview and analysis.

Key words: solar patterns, sun signage, ornaments, styling, emerging and dying spirals, spiral curving.

Introduction

When examining taraz of New Jugha, a pattern, unique in its kind, made on the clothing was worth attracting attention / pic. 1 /. The pattern is a circle with lines inside that resemble the eternity.

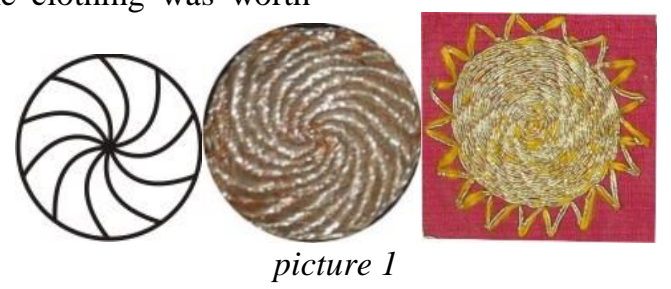

Circle pattern with different stylistics are popular still from Chalcolithic age. One could meet similar patterns on different items discovered from excavations, which were attributed as the sacrament of heavenly luminaries 1/pic.2/:
Circle or disc can also be met in Urartian culture, where charts and patterns are most probably replacing the sign of "sun"/god/ and acts as a separate sign2.

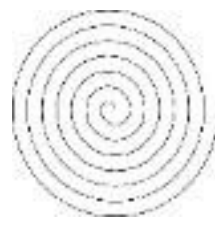

Similar images are also met in petroglyphs. Here one can see different symbolic linear expressions connected with sun cult, which are radial, trochate

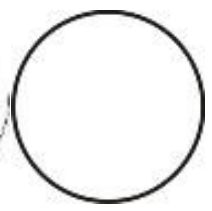

circle - sun, eternal rotation, seed - grain3 circles, circles that are spiral shaped resembling curved cross, with a cross drawn inside, circles with dot.

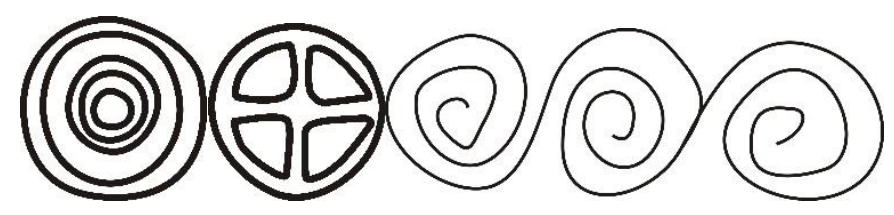

According to H. Mnatsakanyan “ ... in old times the disc of the sun was depicted as a wheel, its rays were depicted as the wheel's bars, and the motion was the rotation of the wheel" 5 .
The cult of the Sun and fire were popular not only in Armenia, but also in whole East. Armenian dwellers worshipped God of sun Mihr, and that is why the people here are called sons of sun6. 